\title{
El estudiante de psicología. La socialización profesional de los futuros psicólogos y la cultura
}

RESUMEN: Estudio para conocer el tipo ideal del estudiante de psicología, de donde surgen diversos perfiles profesionales relacionados con diferentes estilos de vida y diferentes estilos de pensar.

PALABRAS CLAVE: Capitalismo, socialización profesional, psicologización, individualismo.
SUMMARY: The identification of the ideal type of the psychology student was the main outcome of this survey. Beside these prevailing representations, additional professional profiles and related life styles and ways of thinking were also identified.

KEY WORDS: Capitalism, professional socialisation, psychologisation, individualism.

En 1938 el sociólogo norteamericano Robert K. Merton publicó en la prestigiosa American Sociological Review un artículo titulado «Estructura social y anomia» que fue enormemente influyente pues proporcionó una brillante tipología de cinco modos de adaptación cultural que, a partir de 1941, cuando Merton ingresó en la Universidad de Columbia, y estrechó sus lazos con Paul Lazarsfeld y con el Applied Social Research, sirvió de orientación a múltiples investigaciones ${ }^{1}$. A juicio de Merton la familia es la principal correa de transmisión de las normas culturales de una generación a otra, pero existen también otras instancias de socialización, como por ejemplo el sistema educativo. De hecho el propio Merton se interesó por el peso de la socialización profesional que recibían los estudiantes en las Facultades de medicina en donde se formaban los futuros médicos ${ }^{2}$. En su estudio sobre El estudiante de Medicina no tuvo sin embargo en cuenta los cinco tipos de relación a la cultura legítima que definió con los términos de conformidad, innovación, ritualismo, retraimiento y rebelión. Y sin embargo el modelo de Merton podría ser operativo para estudiar las relaciones que existen entre el origen social de los estudiantes, los modos de socialización imperantes en las Facultades, y su relación con la cultura. En función de la adecuación de los medios culturales a los fines, la población en general, y más concretamente los estudiantes, podrían

1 Cf. Merton, R. K., «Social Structure and Anomie», American Sociological Review, 1938, 3, pp. 672682. El artículo revisado fue incluido en el libro Merton, R. K., Teoría y estructura sociales, México, F. C. E., 1973, pp. 209-239, así como en VV.AA., La familia, Barcelona, Península, 1978, pp. 67-106. Véase también LaZARsfeld, P. F.; Sewll, W. H.; Wilensky, H. L. (comp.), La sociología en las profesiones, Buenos Aires, Paidós, 1971.

2 Cf. Merton, R. K., «Some Preliminaries in a Sociology of Medical Education», en Merton, R. K.; Reader, G. R.; Kendall, P. L. (eds.), The Student Physician, Cambridge, Harvard University Press, Mass, 1957, pp. 3-79. 
ser predominantemente definidos como conformistas, innovadores, ritualistas, retraídos y rebeldes ${ }^{3}$.

Al año siguiente, en 1939, el también influyente sociólogo norteamericano Talcott Parsons publicó otro conocido artículo titulado «Las profesiones y la estructura social» en el que afirmaba que el empuje de la división social del trabajo en las sociedades industriales, junto con el peso cada vez más importante que recae sobre el desarrollo y la transmisión del conocimiento científico en las sociedades secularizadas, han proporcionado a las profesiones un protagonismo hasta ahora desconocido en la historia del mundo moderno. Sin embargo ese protagonismo real ha quedado eclipsado por la primacía que generalmente se reconoce al mundo económico en la configuración de una sociedad. A juicio de Parsons el desarrollo de las profesiones no responde tanto a intereses económicos egoístas, propios de una acquisitive society, cuanto a una voluntad de prestar servicios a los pacientes o a los clientes a partir de unas competencias técnicas y científicas adquiridas mediante la socialización profesional. En las profesiones la racionalidad profesional y los valores universalistas predominan sobre el egoísmo y los valores particularistas. El predominio del interés económico de los industriales y banqueros en el mercado deja paso a la centralidad, en la sociedad de las profesiones liberales, al reconocimiento de la autoridad técnica y moral basada en las prestaciones de servicios. Bastantes años después, en 1968, Parsons elaboró otro artículo sobre las Profesiones para la Enciclopedia Internacional de Ciencias Sociales en el que señalaba que la profesionalización constituye un cambio fundamental en el interior del sistema de empleo de las sociedades industriales, hasta el punto de que, desde el punto de vista de las transformaciones estructurales de nuestras sociedades, el fenómeno de la profesionalización supera en significación a la especificidad de los modos de organización bajo el capitalismo o el socialismo. Al fin Talcott Parsons, gracias al irresistible avance de las profesiones liberales, podía legitimar la racionalidad imperante en el sistema social capitalista ${ }^{4}$.

En la actualidad, cuando asistimos a un fuerte empuje de las nuevas tecnologías, cuando la revolución del tejido productivo se intensifica y el viejo mundo surgido de la Segunda Guerra Mundial se deshace, cuando retorna con fuerza la cuestión social, es decir, la posibilidad de que nuestras sociedades se rompan, crece la sensación de incertidumbre y miedo por lo que las profesiones de ayuda,

\footnotetext{
3 En los años sesenta y setenta el modelo mertoniano de sociología funcionalista se vio obligado a coexistir con los análisis sociológicos producidos por los sociólogos críticos. Recuérdese en este sentido el estudio de Bourdieu, P.; Passeron, J. C., Los estudiantes y la cultura, Barcelona, Labor, 1973.

4 Cf. Parsons, T., «The Professions and Social Structure», Social Forces, 1939, 17, pp. 457-467. El artículo ha sido retomado en PARsons, T., Essays in Sociological Theory, Nueva York, The Free Press, 1964, pp. 34-49.
} 
como la medicina, la psicología, o el trabajo social, recobran un nuevo protagonismo para hacer frente a nuestros problemas y malestares.

En términos generales se puede decir que la profesión de psicólogo se integra en el interior de las nuevas profesiones universitarias frente a las viejas profesiones liberales que cuentan ya con una larga tradición histórica, como las figuras del jurista o del médico. La psicología, en tanto que profesión universitaria, es decir, en tanto que profesión que para ser ejercida requiere previamente la obtención de un título universitario, forma parte de los nuevos saberes científicos sobre el psiquismo humano, y presenta conexiones con la medicina y la biología, pero a la vez se abre a los sujetos de una sociedad, a sus pensamientos, sentimientos y conductas, en tanto que seres sociales. Así pues la psicología se encuentra en una posición ambigua e inestable entre las ciencias de la vida y las ciencias sociales y políticas, entre la naturaleza y la cultura. La psicología es una profesión de ayuda y de cuidado. Aspira a formar parte de las ciencias de la salud, como han puesto de manifiesto las movilizaciones protagonizadas por los psicólogos en los últimos tres años que contaron con el apoyo del Colegio de Psicólogos, pero a la vez los psicólogos están presentes en las cárceles, en los hospitales y escuelas, actúan como correctores de las desviaciones, como terapeutas, y, en general, se presentan como profesionales integrados en una profesión de reparación.

Son más de treinta las Facultades de psicología existentes en nuestro país, tanto en las Universidades públicas como en las privadas, en las que estudian cerca de 60.000 estudiantes que aspiran a ser profesionales de la psicología, pero no sabemos demasiado sobre su origen social, sus valores y su relación con la cultura. No abundan en España los estudios sobre la socialización profesional de los universitarios, y menos aún existe un Observatorio de la Vida Estudiantil, como por ejemplo el OVE, un organismo público creado en Francia, y que desde 1994, cada tres años, realiza una encuesta que permite detectar regularidades y cambios en el mundo social de los futuros profesionales. Los datos procedentes de las encuestas no sólo permiten conocer mejor el desconocido universo social de los estudiantes y sus problemas, sino que, a la vez, pueden contribuir a orientar eventuales mejoras, así como reformas legítimas de las políticas educativas ${ }^{5}$.

\footnotetext{
5 El sociólogo francés Claude Grignon fue Presidente del Comité científico del Observatoire de la Vie Étudiante (OVE), y autor o coautor de una serie de monografías. Cf. por ejemplo GriGNON, Cl.; GRUEL, L.; Bensoussan, B., Les conditions de vie des étudiants, Enquête 1994, París, La documentation française, 1996. A esta encuesta respondieron cerca de 28.000 estudiantes en Francia. Véase también Grignon, C., La vie matérielle des étudiants. Logement, alimentation, santé, París, La documentación française, 1998, así como GRIGNON, C.; GruEl, L., La vie étudiante, París, PUF, 1999. En España un estudio pionero sobre la socialización profesional de los maestros fue realizado por VARELA, J.; ORTEGA, F., El aprendiz de maestro. Un análisis sociológico de los estudiantes de magisterio del distrito universitario de Madrid, Madrid, Ministerio de Educación y Ciencia, 1984. La Revista Papeles del Psicólogo ha publicado diferentes estudios sobre el perfil profesional del psicólo-
} 


\section{Los estudiantes de psicología y la autoridad}

Durante los tres últimos años hemos realizado una investigación sobre $L a$ psicologización del yo en la sociedad de los individuos. Uno de sus principales objetivos era intentar abordar la cuestión de la psicologización dando un rodeo en el espacio y en el tiempo a partir de un trabajo de sociología histórica, pero siempre movidos por un intento de reflexionar sobre un problema del tiempo presente. En este sentido realizamos algunas entrevistas y grupos de discusión con estudiantes universitarios. El trabajo de campo realizado a partir de los grupos de discusión, así como la pre-encuesta, nos permitió comprobar que una minoría de los componentes de los grupos estaban formados por sujetos que podríamos definir como psicologizados. Cuando nos referimos a la psicologización del yo no aludimos tanto a procesos sociales relativos a personas que han sido objeto de tratamientos psicológicos o de psicoterapias, cuanto a determinados estilos de vida y a determinados estilos de pensar - por utilizar la expresión de Mary Douglas- propios de individuos que tienden a encerrarse sobre sí mismos y buscan en sí mismos, es decir, en su mundo interior, en su alma, convertida en una especie de fortaleza que los protege del exterior, una razón para vivir, pues han elegido vivir para buscar incesantemente dentro de sí una especie de inagotable tesoro escondido

Nos preguntábamos si en la elección de la profesión de psicólogo podía tener algún peso la problematización del yo que por lo general se produce, en nuestro universo cultural, en el periodo de transición de la infancia a la edad adulta. De hecho, a medida que avanzaba la investigación, nos hacíamos las siguientes preguntas: ¿Cómo y por qué se produce la desvinculación de unos sujetos de su mundo social? ¿A qué responde la apertura de ese espacio interior? ¿A qué grupos sociales afecta fundamentalmente la psicologización del yo, y por qué? ¿Qué

go. Véase por ejemplo Sierra, J. C.; Bermúdez, M. P.; Teva, I.; Agudelo, D.; Breton-López, J., y otros, «Imagen de la psicología como profesión sanitaria entre los estudiantes de psicología», Papeles del psicólogo, 2005, 91. Proporcionan interesantes datos Buela Casal, G.; Álvarez-Castro, S.; Sierra, J. C., «Perfil de los psicólogos de la última promoción de las universidades españolas», Psicología conductual, 1993, 11, pp. 81-206, así como Hernández Gordillo, A., «Los estudios universitarios de psicología en España», 1, Papeles del psicólogo, 2003, 86, pp. 13-24.

6 Entre algunas de las publicaciones generadas por la investigación véase ÁlVAREZ-URÍA, F., «Viaje al interior del yo. La psicologización del yo en la sociedad de los individuos», Claves de la razón práctica, 2005, 153, pp. 61-67; VARELA, J., «El descubrimiento del mundo interior», Claves de la Razón Práctica, 2006, 161, pp. 4248; así como Gordo, Á., «Función de las Nuevas Tecnologías en la Construcción de la Identidad: Una mirada cualitativa desde la Emoción y el Tacto», en BAUTISTA, A. (ed.), Las nuevas tecnologías en la enseñanza, Universidad Internacional de Andalucía, Akal, 2004, pp. 61-77, así como GoRdo, Á. (dir.), Jóvenes y cultura messenger, Madrid, Injuve, 2006. Sobre la psicologización del mundo social véanse también los trabajos de Rose, N., Governing the Soul: the Shaping of the Private Self, Londres, Routledge, 1990, así como RENDUELES, G., Egolatría, Oviedo, 2005. La revista Archipiélago publicará en julio del 2007 un número monográfico sobre las funciones sociales de la psicología. 
conductas, qué valores y qué formas de percibir el mundo se derivan de adoptar este estilo de vida? Los grupos de discusión y las entrevistas realizadas hasta entonces no nos permitieron responder de un modo concluyente a estas cuestiones. Ésta fue la principal razón por la que en nuestro tercer año, en abril de 2005, decidimos combinar los análisis cuantitativos con los análisis cualitativos de los que ya disponíamos. Para ello elaboramos un cuestionario formado por 83 ítems al que respondieron estudiantes de la Facultad de Psicología de la Universidad Complutense de Madrid. La muestra se compuso de un total de 412 estudiantes de ambos sexos matriculados en los cinco cursos de Licenciatura. En ella estaban representados los turnos de mañana y de tarde, así como los cinco cursos con sus correspondientes especialidades diferentes ${ }^{7}$. Uno de los principales objetivos de la encuesta era realizar un análisis de las respuestas que nos permitiese discriminar el peso de las distintas instituciones en el proceso de adopción por una parte de los individuos de un estilo de vida psicologizado. Vamos a presentar ahora algunos de los principales resultados de la encuesta que pueden no solo proyectar alguna luz sobre las cuestiones que nos planteábamos, sino también contribuir a enriquecer el perfil profesional de los futuros psicólogos.

Parodiando a un sociólogo norteamericano que afirmaba que la sociología es lo que hacen los sociólogos se podría decir que la psicología es lo que hacen los psicólogos. La psicología es entendida por unos como la ciencia de la mente, mientras que otros tienden a definirla como la ciencia de las conductas; en fin, desde una perspectiva más psicosocial, algunos identifican a la psicología con la ciencia del hombre en sus relaciones con el entorno físico, social y cultural.

Sabemos que existen distintos códigos psicológicos, sabemos que el campo psicológico está formado por distintas escuelas de pensamiento, pero es menor nuestro conocimiento de los profesionales que se dedican a las teorías y a las prácticas psicológicas. ¿Quiénes son los futuros psicólogos y qué hacen? ¿Cuál es su origen social y su posición social? ¿Cuál es su sistema de valores? ¿Cómo evalúan la socialización profesional que reciben en la Facultad? ¿En fin, cuáles son los principales rasgos de su mundo cultural y político? Nos limitaremos aquí tan sólo a señalar algunos de los principales rasgos que presenta el perfil profesional, social y cultural de los futuros profesionales de la psicología elaborado a partir de los

7 La elaboración de la encuesta, así como su aplicación a una muestra de algo más de seiscientos estudiantes de la Universidad Complutense corrió a cargo de los miembros del equipo de investigación Fernando Álvarez-Uría, Julia Varela y Ángel Gordo. En la muestra estaban representados los estudiantes de la Facultad de Psicología (412 encuestados) y elegimos como contrapunto a los estudiantes de la Facultad de Sociología (203 encuestados). Todos ellos están matriculados en el Campus de Somosaguas de la Universidad Complutense de Madrid. Para el enmaquetado de la pre-encuesta y de la encuesta contamos con el asesoramiento y la colaboración de la profesora Lucila Finkel del Departamento de Sociología IV de la Universidad Complutense. 
datos recogidos en la encuesta, y esperamos que esta información sirva de estímulo a futuras investigaciones.

A partir de la variable sociabilidad, con dos polos que van del individualista e introvertido al sociable y extrovertido, combinada con la variable de la autoridad, también con dos polos que van del partidario de la autoridad legítima al contrario a toda autoridad, hemos podido establecer cuatro grandes grupos de estudiantes. Por un lado estarían dos grupos moderados que aceptan las pautas de la cultura legítima: el liberal, individualista e introvertido, pero partidario de la autoridad legítima, y el socialdemócrata, sociable y extrovertido, y también partidario de la autoridad legítima; por otro, nos encontramos con dos grupos radicales que, parodiando a Mary Douglas, podríamos decir que han adoptado la diagonal negativa: el outsider, individualista e introvertido, contrario a toda autoridad, y el libertario (podríamos añadir libertario comunitarista o societario, para diferenciarlo del outsider), que es sociable y extrovertido, y a la vez contrario a toda autoridad. Nos servimos del término inglés outsider no en el sentido de marginal desviado que utilizó por ejemplo el sociólogo norteamericano Howard Becker para designar a los jóvenes delincuentes, sino más bien para designar al estudiante que vive un tanto fuera del espacio social, y a la vez ensimismado en su mundo interior. Estos grupos coincidirían en buena medida con los que Merton denomina retraídos y rebeldes, mientras que los dos anteriores coincidirían más con los innovadores y conformistas. Podemos representar a los cuatro grupos en el siguiente cuadro de doble entrada:

\begin{tabular}{lcc}
\hline & Cultura legítima & Contracultura \\
\hline Individualismo & Liberal & Outsider \\
\hline Comunitarismo & Socialdemócrata & Libertario Societario \\
\hline
\end{tabular}

La inmensa mayoría de los estudiantes de psicología se caracterizan por ser sociables y extrovertidos $(63,3 \%)$ y partidarios de la autoridad legítima $(66,5 \%)$, pero mientras que los individualistas aumentan a medida que se asciende en la estratificación social, los contrarios a toda autoridad descienden a medida que se asciende en la estratificación social.

En el cuestionario se pedía a los estudiantes que se definiesen en torno a los siguientes cuatro estilos de vida: tradicional-conservador, libertario-individualista, competitivo-liberal y participativo-socialista. El resultado obtenido fue el siguiente: el 10,7\% de los estudiantes, con casi el doble porcentaje de chicos que de chicas eligió definirse como tradicional-conservador; el 7,8\%, con mayor porcentaje de chicos que de chicas, se definió como libertario-individualista; el 13,6\%, con mayor porcentaje de chicos que de chicas como competitivo-liberal; y el 67\%, con mayor 
DEBATES E INFORMES

porcentaje de chicas que de chicos, como participativo-socialista. En términos generales se puede afirmar que los chicos son más individualistas y radicales que las chicas, pero también más conservadores y problematizados. Las chicas, partidarias del reformismo, tienen mayor confianza en el futuro y optan por una posición más adaptativa y moderada frente a los chicos que tienden a los extremos, es decir, al conservadurismo y al intimismo. Casi el doble de chicos que de chicas afirman poder definirse a sí mismos como defensor de mi mundo personal, y el porcentaje aumenta a medida que se asciende en la escala de estratificación social.

Aunque nuestro objetivo es presentar una especie de caracterización sociológica de los futuro psicólogos, su origen social, su socialización, y su cultura, nos detendremos también, al final del texto, en ahondar un poco más en la caracterización de los estudiantes outsiders, es decir, los estudiantes más psicologizados que también podríamos caracterizar como los bohemios retraídos en honor a la tipología de Merton. Fueron ellos los que, preocupados por su propia identidad en riesgo, constituyeron el punto de partida de la encuesta.

Todo perfil profesional no deja de ser un tipo ideal, en el sentido que confirió a este concepto Max Weber, de tal forma que el prototipo de estudiante que vamos a presentar no existe, es una elaboración nuestra, pero no ha surgido de la nada, sino que ha sido identificada a partir de las respuestas que los propios estudiantes proporcionaron cuando voluntariamente respondieron al cuestionario. Así pues presentamos un tipo ideal que no deja de tener un fundamento en la realidad. Sin duda no todos los estudiantes se reconocerán en las figuras que aquí quedan dibujadas. Sin embargo este retrato robot con bases empíricas contribuirá a definir y conocer mejor quiénes son los psicólogos en formación, que eligen esta profesión, por qué la eligen, cuál es la concepción que tienen del mundo en el que viven y cuáles son sus valores. Sería preciso ampliar el universo de la muestra, algo más de 3.000 estudiantes, a otras universidades, tanto públicas como privadas, para validar ese perfil que proponemos como el perfil dominante entre los estudiantes de psicología que estudian en las universidades españolas, y que en el curso 2005-2006 alcanzaban prácticamente los 56.000 estudiantes universitarios matriculados, es decir, casi 3.000 menos que en el curso 2000-20018.

8 En el curso 2006-2007 hay, según las estadísticas de la Facultad de psicología, 3.242 estudiantes matriculados en la Complutense repartidos del modo siguiente en función de los cursos:

Curso Primero

Curso Segundo

Curso Tercero

Curso cuarto

Curso quinto

Mujeres
467
429
487
448
843

Total

585

530

573

544

1.010 


\section{El origen social de los estudiantes y sus familias}

El estudiante medio de psicología es una mujer joven (un $84,3 \%$ de los estudiantes son mujeres, frente a un $15,7 \%$ que son varones). La feminización de la profesión se deriva en buena medida de que se trata de una profesión de ayuda. La edad media de estas jóvenes estudiantes ronda en torno a los 20 años. Por lo general los estudiantes viven con sus padres, en un piso que es propiedad de los padres y que con frecuencia se encuentra ubicado en un barrio de la periferia de Madrid. En su mayoría estas jóvenes estudiantes que aspiran a ser futuros profesionales, y que han accedido a la Universidad, realizaron la ESO en un centro público de enseñanza, y, todavía en una mayor proporción, estudiaron el bachillerato en un Instituto público.

Sus familias proceden, en la mayoría de los casos, de las clases populares, es decir, de las clases trabajadoras. Tan sólo un $10 \%$ proceden de familias de la burguesía tradicional. Sus padres y abuelos nacieron mayoritariamente fuera de Madrid y financian los gastos de sus hijos, la manutención y la matrícula, además de proporcionarles dinero para los gastos durante el curso, unos gastos que ascienden a una media de unos treinta euros semanales. Sus padres poseen predominantemente estudios primarios o de bachillerato, si bien un $34,5 \%$ de los padres y un $23,8 \%$ de las madres han obtenido un título universitario. Sin embargo tan solo un $9,2 \%$ de los abuelos varones paternos y un 7,8\% de los abuelos varones maternos accedieron a los estudios universitarios. Proceden por tanto de familias en las que se ha producido una cierta movilidad social basada en los estudios, gracias a la apertura que, durante el franquismo, se produjo a partir de la aprobación de la Ley Villar en 1970. Los abuelos de los estudiantes proceden de zonas rurales y vinieron a Madrid en busca de trabajo, tras el Plan de Estabilización de 1959, y bajo el empuje de los planes de desarrollo. El padre trabaja a tiempo completo, sobre todo como administrativo, empleado, o técnico de grado medio, seguido de aquellos padres que realizan un trabajo manual: albañil, fontanero, etc. La mitad de las madres son amas de casa, y la otra mitad trabajan a tiempo completo, y su empleo más frecuente es el administrativo en una oficina o en la administración pública, seguido de un trabajo también en el sector servicios: limpieza, sanidad, cuidado de niños, etc.

Los ingresos mensuales de la familia oscilan entre los 2000 y los 3000 euros. Giran, por tanto, en torno a una media de unos 2500 euros. Entre las propiedades de la familia se encuentra el coche y la plaza de garaje en propiedad, el piso en propiedad desde hace años, y una de cada tres familias continúan siendo propietarios de una vivienda en el pueblo. Un porcentaje también importante poseen una segunda vivienda en la sierra o en la playa (24\%), lo que, dado el acelerado incremento del precio de la vivienda en estos últimos años, los hace sentirse ricos, y por 
DEBATES E INFORMES

tanto moderadamente conservadores. De hecho la inmensa mayoría de los estudiantes se ubican a sí mismos en las clases medias. A ello contribuye sin duda el importante crecimiento de la emigración en Madrid durante los diez últimos años. Esto es todavía más visible cuando se les pregunta a los estudiantes por su clase social subjetiva, pues casi el $60 \%$ se sitúa en la clase media-alta. La inmensa mayoría de las familias de los estudiantes viven con un cierto desahogo económico pues tienen lavavajillas, TV, vídeo, cámara de vídeo, cámara de fotos, microondas, teléfono móvil, equipo de música y ordenador, aunque únicamente un tercio de estas familias está conectado con la red. En un tercio de las familias suele haber algún animal mascota, predominantemente perros, pero también gatos. Casi en la totalidad de las casas existen diccionarios y enciclopedias, pero una familia de cada tres no cuenta con una biblioteca formada por un mínimo de cien libros, lo que indica que el capital cultural familiar de los estudiantes es, en un porcentaje muy significativo, más bien bajo. De hecho, cuando se les pregunta qué movilidad social esperan tener respecto a la posición social de su familia, un 54,6\% responde que espera poder mantener la misma situación social que sus padres, mientras que el $42,7 \%$ percibe la profesión de psicólogo como una clara vía de ascenso social, pese a que son conscientes de las dificultades que existen para encontrar trabajo una vez que han obtenido el título universitario9.

Un dato que consideramos relevante es que cuando se les preguntó por los estudios o por la profesión de sus abuelos los porcentajes de no sabe, no contesta, superaron el $30 \%$. Encontramos por tanto que un alto porcentaje de estudiantes están, como ya se ha señalado, afincados en Madrid, pero proceden de familias del mundo rural cuyos padres y abuelos emigraron a la capital y rompieron los lazos con la tierra natal.

Estos estudiantes universitarios son conscientes de que estamos asistiendo a una transformación importante del mundo social y de que se están generando nuevas formas de familia, como pone de manifiesto la nueva la ley de matrimonios homosexuales. Su ideal de familia es una familia moderna, democrática, es decir, aquella en la que las decisiones se negocian entre todos. Así pues el $46 \%$ dice pertenecer a familias democráticas, y casi un tercio afirma que en su familia son el padre y la madre quienes ejercen la autoridad de forma compartida. La familia tradicional, de fuerte impronta patriarcal se encuentra en franca minoría. Sin embargo domina entre estos jóvenes la aspiración a independizarse y contar con

9 Se podría avanzar la hipótesis de que la elección de carrera refleja en buena medida la posición social acompañada de la ausencia de información sobre las salidas profesionales de los estudios de psicología, una profesión en la que los índices de paro son altos. Y es que la información y la elección de titulaciones con mejores salidas profesionales aumentan a medida que se asciende en la escala de estratificación social de las familias. Cf. Dubar, C., La socialisation. Construction des identités sociales et professionnelles, París, Armand Colin, 1996. 
una vivienda propia. Cuando se les pregunta con quién les gustaría vivir si contasen con medios suficientes, únicamente un $1 \%$ responde que con sus padres. A la mayoría, el 40,8\%, les gustaría vivir con un compañero o compañera. Y casi un $30 \%$ con su esposo o esposa e hijos, lo que implica un fuerte deseo de independizarse y de gozar de una autonomía y estabilidad profesional, algo que resulta problemático debido a la actual precarización del trabajo, y a la saturación del mercado laboral, especialmente refractario en el caso de los psicólogos clínicos, la especialidad que eligen la inmensa mayoría.

A la hora de optar por una posible vivienda la mayoría se decanta por un ático con terraza en el centro de la ciudad (casi un 40\%), seguido por un piso en una urbanización de las afueras de Madrid. El ático presenta la ventaja de no tener vecinos encima, y a la vez resulta más económico que el resto de los pisos. También permite ver la ciudad desde lo alto y desde la distancia. Los gustos en la decoración se corresponden en buena medida con los de las nuevas clases medias con mayor capital cultural que los capitales de las clases populares pues les gustaría que su piso fuese moderno y funcional, con una decoración que ellos mismos definen como práctica, confortable, funcional, un poco al estilo de IKEA, pero sobre todo íntima y personal.

Para estos jóvenes la familia sigue siendo no obstante un refugio en un mundo despiadado, como la definió el historiador norteamericano Christopher $\operatorname{Lasch}^{10}$. Sin embargo un 12,5 de las familias son familias en las que predominan los conflictos (7,3\%) o familias convertidas en un espacio físico de convivencia en el que cada uno va a la suyo $(5,1 \%)$. Curiosamente las rupturas familiares están sobre-representadas entre los estudiantes varones que son también el colectivo más psicologizado.

\section{Gustos, consumos, cultura y ocio}

Entre las actividades que realizan los estudiantes, además de estudiar, destacan, siguiendo este orden, pasear por la ciudad, fumar, oír la radio, oír música moderna, ver la TV, ver películas en vídeo, leer novelas, leer la prensa, bailar, practicar algún deporte, ir de copas, ir al cine, etc. En todo caso son pocos los que realizan un trabajo de voluntariado, los que consumen drogas (un 70\% afirma no haberlas probado nunca), escuchan música clásica, asisten a conciertos o van a la ópera, tocan un instrumento musical, juegan a la lotería, leen poesía, leen libros de ensayo, leen cómics, escriben poesía, escriben un diario, van al teatro, van a exposiciones, realizan viajes al extran-

10 Cf. Lasch, C., Refugio en un mundo despiadado, Barcelona, Gedisa, 1984. Véase también el libro de Sloan, T., Damage Life. The Crisis of the Modern Psyche, Londres, Routledge, 1996. 
DEBATES E INFORMES

jero, van a misa. Son por tanto estudiantes que se podrían caracterizar como modernos, europeos, procedentes en su mayor parte de una clase media baja, con escaso capital cultural, y sin embargo movidos por un fuerte voluntarismo vocacional.

En algunos casos ayudan en casa a hacer la compra, actividad en la que, según afirman, colaboran más los chicos que las chicas, quienes también dicen ayudar más a fregar los platos. Sin embargo tanto ayudar en la cocina, la limpieza de la casa o planchar parecen ser tareas predominantemente femeninas. Pero, en términos generales, se puede afirmar que tanto chicos como chicas colaboran poco en el mantenimiento de las casas familiares de las que se ocupan especialmente las madres.

A la hora de elegir novelas, su lectura más frecuente, los chicos se decantan por las novelas de aventuras y las chicas por las románticas. Y un porcentaje significativo, el 63\%, afirma que le gusta la literatura de terror. Si tuviesen que regalar un libro a un amigo elegirían El código Da Vinci, seguido de Cien años de sole$d a d$. Las películas que prefieren son las psicológicas y las de suspense, y las que menos les interesan son las del oeste, seguidas del cine bélico, especialmente en el caso de las chicas. Los programas de TV que prefieren son las películas, seguidas de Aquí no hay quien viva, Los Serrano, y los informativos. Su música predilecta es la música pop, seguida de ritmos latinos y del rock. Y la que menos les gusta es el bacalao, la zarzuela, la ópera, el flamenco, y la música clásica. Su pintor favorito es Dalí, seguido de Van Gogh y de Goya.

Respecto a la cocina eligen la española muy mayoritariamente, y ello más los chicos que las chicas que se muestran más cosmopolitas. En segundo lugar prefieren la comida italiana. Les gusta la cocina tradicional de la abuela, pero también las tapas, y en torno a un $2 \%$ se declaran vegetarianos, una proporción parecida a los que eligen la cocina rápida estilo McDonalds.

Por lo que se refiere al sistema de valores los estudiantes están a favor del matrimonio homosexual (el 81,8\%), y más de acuerdo aún con el divorcio $(96,6 \%)$, la igualdad entre los sexos $(96,8 \%)$, en contra de la guerra de Irak $(94,2 \%)$, a favor de las parejas de hecho $(89,3 \%)$, a favor de las relaciones sexuales libres $(85 \%)$, a favor del reparto de las tareas domésticas entre hombres y mujeres $(98,5 \%)$, la eutanasia $(84,7 \%)$, el aborto $(76,7 \%)$. Se muestran favorables al control público de la telebasura $(71,6 \%)$. Están masivamente en desacuerdo con la venta de armas (96,8\%), y en una proporción elevada también están en desacuerdo con la obligatoriedad de la asignatura de religión en la ESO (73,8\%), así como con la financiación de la Iglesia por parte del Estado (76\%), sin embargo aprueban en una proporción similar la financiación pública de las ONG. Domina también entre estos estudiantes, aunque más moderadamente, una tendencia al laicismo, que aprueban en un porcentaje del $58,5 \%$. Respecto a la emigración son favorables a una regulación de la misma $(82,5 \%)$, y cuando se les pregunta por los derechos de ciudadanía de los emigrantes, concretamente por el derecho al voto, 
están de acuerdo un 63,8\%, si bien son mayoritariamente favorables a la persecución de la inmigración ilegal $(53,2 \%)$. Los estudiantes se muestran sensibilizados respecto a problemas tales como el terrorismo frente al que proponen una política de mano dura. El 76\%, se declara a favor de la ilegalización de Batasuna. A pesar de que en una proporción mayoritaria están en desacuerdo con la pena de muerte $(78,2 \%)$, un porcentaje alto del $74 \%$ se muestra favorable a la cadena perpetua para los terroristas. En su mayoría se muestran contrarios a los movimientos nacionalistas $(56,6 \%)$. En relación con la Constitución europea predominan los que se muestran favorables a ella, el $41,7 \%$, aunque hay un alto porcentaje que se muestra indiferente $(37,1 \%)$. Rechazan la privatización de las empresas públicas casi un 70\%, y apuestan muy decididamente por un Estado social, pues el 90,5\% defiende una renta mínima asegurada para todos. Sin embargo de sus respuestas no se deduce muy claramente cuáles van a ser las fuentes de financiación de esa renta, pues cuando se les pregunta acerca de la reducción de impuestos responden que están de acuerdo un $72,6 \%$. Se manifiestan a favor el reparto del trabajo el $98,3 \%$, y contrarios a la reducción de las políticas sociales el 56\%.

Cuando se les pregunta acerca de cuál es el principal problema que tienen los jóvenes en la actualidad, se refieren en primer lugar al problema de la vivienda, seguido del problema del paro, la precarización laboral y las drogas. Una vez más se confirma que tienen un fuerte deseo de independizarse, un deseo que lógicamente aparece vinculado al trabajo y a la vivienda. Son conscientes de que la oferta de empleo para los psicólogos en el mercado de trabajo existente no es suficiente para responder al creciente número de licenciados en psicología. Como escribía recientemente un estudiante de la Universidad Complutense: «Las empresas cada vez crecen más, y el fantasma de la tecnología se apodera de trabajos que antaño correspondían a seres humanos. El paro se cierne sobre nosotros abrazándonos uno a uno. En mi caso soy estudiante de Psicología y todo se ve muy negro. Cada vez exigen más para poder ejercer, y hay demasiada demanda para lograr un solo puesto puntual. No soy un experto en estos temas, pero cuando mis padres vinieron a vivir a Madrid siendo jóvenes no tenían ningún problema en elegir y lograr el empleo que quisieron. Hoy en día la gente está mejor preparada, y lo tiene mucho más difícil. Las soluciones son pocas y muchas veces parecen inviables» ${ }^{11}$. No se trata de un problema exclusivo de los futuros psicólogos. Según datos recientes de la OCDE (2007) el 60\% de los licenciados españoles realizan trabajos que tienen poca o ninguna relación con su formación.

11 Comentario del libro Los parados de Marienthal realizado por un estudiante varón de $4 .^{\circ}$ curso de Psicología Clínica de la Universidad Complutense en un trabajo para la asignatura de libre configuración Sociología de la pobreza. 
Cuando se les pregunta cuál es la principal raíz de la delincuencia común responden mayoritariamente que es el entorno en el que se mueven los delincuentes, aunque las chicas se muestran más sensibles al deterioro familiar, y a la permisividad del sistema judicial, así como a las situaciones de explotación y miseria. Afirman que uno de cada tres chicos ha sido objeto de algún atraco, mientras que entre las chicas la proporción es del 11,5\%. El ataque violento también es sufrido doblemente por los chicos que por las chicas. Y también éstos dicen haber sido más acosados en la escuela: $20 \%$ frente a $15 \%$. La proporción es mayor cuando se refiere al ataque informático de los hackers, $27,7 \%$, frente a $13 \%$. Casi la mitad de los estudiantes dice haber sido objeto de algún robo: los chicos han sufrido más robos que las chicas: $53,8 \%$ frente a $45 \%$, y también han sufrido en mayor número amenazas: $53 \%$ frente a $27 \%$. De esto parece derivarse que en el mundo de la calle, y, especialmente en el mundo de la noche, existe una gran violencia, especialmente entre los chicos. Para combatir la delincuencia, que perciben espontáneamente como el resultado de una especie de asociación diferencial de pandilleros agresivos, proponen fundamentalmente combinar las políticas de prevención con los tratamientos penitenciarios dirigidos a una reinserción eficaz.

Lo que más valoran es la vida familiar (52,9\%), seguida de su profesión, pues el éxito social y profesional, así como la formación intelectual, ocupan un segundo lugar. Los estudiantes valoran mayoritariamente también el peso de lo social y de la sociedad, y se muestran dispuestos a trabajar en favor de una sociedad más justa. Existe no obstante un porcentaje significativo de estudiantes, en torno a un $14 \%$, muy interesado en descubrir su propio mundo interior, en el que nos detendremos, como ya dijimos, más adelante pues constituyen el grupo de los estudiantes que hemos caracterizado como psicologizados.

Veamos ahora cómo jerarquizan los estudiantes los siguientes cuatro tipos de capital: capital económico, capital cultural, capital relacional y capital psicológico. El primer lugar, es decir, el más valorado es el capital relacional, es decir, las relaciones familiares, de amistad, y sociales; en segundo lugar se sitúa el capital psicológico, entendido como riqueza interior; en tercer lugar figura el capital cultural, entendido como conocimientos y títulos académicos; y por último está el capital económico, es decir, el dinero. Así pues el altruismo predomina sobre el egoísmo; los valores postmaterialistas se imponen sobre el materialismo del dinero, la mercancía más preciada en una sociedad que podría ser caracterizada como capitalismo de consumo. Se muestran en una muy elevada proporción como gente abierta, partidaria de la negociación, de la participación y el consenso, aunque un porcentaje, que ronda el $7 \%$, se definen como competitivos y liberales, y un porcentaje del $14 \%$ como defensores de su mundo personal. Esta última proporción domina sobre todo en el caso de los chicos. Se manifiestan mayoritariamente no creyentes, aunque uno de cada tres dice ser creyente no practicante y tan solo 
el $7 \%$ creyente practicante. La proporción de creyentes practicantes resulta especialmente baja si se piensa que la mayoría de los padres de los estudiantes rezaron diariamente en su infancia el rosario en familia ${ }^{12}$.

\section{El universo social y político de los estudiantes}

Desde el punto de vista político la inmensa mayoría de los estudiantes de psicología se declaran demócratas y progresistas. Tan sólo un 3\% se definen a sí mismos como conservadores. En el otro polo un $6 \%$ se definen como revolucionarios.

Cuando se les pregunta por las formas de gobierno, el 55,6\% se decanta por la república, y el $39,3 \%$ por la monarquía constitucional. Un 3\%, mayoritariamente chicos, se declara libertario. Un $2,7 \%$ afirma pertenecer a la izquierda radical, y un 45,9\% de los futuros psicólogos se definen a sí mismos como de izquierda moderada. El 16,7\% afirma situarse en el centro, y el 8,5\% en la derecha moderada. Sin embargo casi uno de cada cuatro, es decir, un $25 \%$, afirman que no les interesa la política y se declaran abiertamente escépticos, apolíticos, o antipolíticos. Frente a ellos la mayoría se definen a sí mismos como demócratas y reformistas progresistas, y piensan que otro mundo es posible. El socialismo democrático, seguido a mucha distancia del republicanismo, constituyen sus principales opciones políticas.

A la hora de calificar a nuestra sociedad la consideran predominantemente cerrada, si bien son conscientes de que se trata de una sociedad compleja. Consideran que vivimos en una sociedad democrática, aunque relativamente bloqueada y muy despilfarradora, poco racional, más bien violenta y desinformada, una sociedad que progresa lentamente. La institución que más valoran es el sistema sanitario, seguida del sistema educativo, la seguridad social y los transportes públicos. Entre las menos valoradas están la iglesia, el sistema penitenciario, el gobierno, el parlamento y la TV. Un poco mejor valoradas quedan la policía y la justicia. Los principales problemas a los que se enfrenta el mundo son para estos jóvenes el de las desigualdades sociales y las guerras, seguido del terrorismo. Y los principales problemas a los que se enfrenta España son el terrorismo, las desigualdades sociales y la pasividad social. Los jóvenes que aspiran a convertirse en los futuros psicólogos se definen a sí mismos como pacifistas, y quizás por esto sienten una especial admiración por Ghandi. Y si en abril de 2005 se convocasen

12 En la Facultad de psicología hay una capilla católica y un sacerdote con cargo al presupuesto de la Universidad que perpetúan la tradición heredada del franquismo. Sin embargo los estudiantes del Campus de Somosaguas no cuentan con un lugar de encuentro, un club cultural, un espacio para conversar, o simplemente para leer los periódicos. 
elecciones generales el PSOE obtendría un $31 \%$ de los votos, IU un 12, 9\% el PP $11,4 \%$, y votarían en blanco el $18 \%$ o se abstendrían un 17\%, manifestándose así un cierto descontento respecto a la política actual. Llama la atención que IU, frente a lo que ocurre en las elecciones generales, aparece con más expectativas de voto que el PP, si bien esas expectativas son mayores únicamente entre las chicas, pues en el caso de los chicos la voluntad de voto respecto al PP es del 15\% frente al $10 \%$ respecto a IU.

¿Por qué prácticamente un $25 \%$ de los estudiantes no se siente representado por los partidos políticos del arco parlamentario, y por qué en un alto porcentaje estudiantes universitarios dan la espalda a la política? ¿Cómo es posible que en un país que sufrió durante décadas una dictadura militar, y que aún no ha democratizado en profundidad sus instituciones, los jóvenes se muestren desencantados de la política? ¿Juega algún papel en el distanciamiento de la política parlamentaria la socialización profesional? Para responder a estas cuestiones sería preciso realizar un análisis más afinado de la encuesta, y muy posiblemente completar el análisis de los datos cuantitativos recurriendo de nuevo a entrevistas y a grupos de discusión. Sin embargo una pista de explicación de la disconformidad política la proporciona el hecho de que los estudiantes se declaren mayoritariamente republicanos $(55,6 \%$ frente a cerca del $40 \%$ que se declaran partidarios de la monarquía constitucional), porcentaje que no deja de expresar una contradicción entre la forma de gobierno legalmente establecida, la monarquía constitucional, y la forma de gobierno deseada, la república parlamentaria. El segundo dato que parece importante es que mayoritariamente, es decir, el 50\% de los estudiantes consideran que el alzamiento militar del 18 de julio de 1936 fue un golpe de Estado ilegítimo contra un gobierno democrático legítimamente constituido. El franquismo aparece por tanto como una reliquia del pasado. Tan sólo un 3,6\% de los estudiantes legitima, en nombre de la corrupción, la sublevación militar contra el gobierno de la II República. Dicho en otros términos, la extrema derecha es prácticamente irrelevante en la Facultad de psicología de la Universidad Complutense.

Es muy posible que los altos porcentajes de apoliticismo y distanciamiento de la política tengan también que ver con que los estudiantes perciben que la clase política está muy alejada de sus intereses, a lo que se suma la sensación de bloqueo profesional, junto con el enriquecimiento fácil en el sector de la construcción. Jesús Gil y Marbella, pero también los promotores de los nuevos barrios de Madrid, son la expresión extrema del éxito económico y social de unos advenedizos con bajo capital cultural. De hecho la desafección por la política es confirmada por un estudio realizado por la Fundación de Ayuda contra la Drogadicción (FAD) y el Instituto de la Juventud (INJUVE) a partir de un sondeo en el que participaron 1.200 chicos y chicas de todas las comunidades autónomas. En este estudio se afirma que seis de cada diez jóvenes entre 15 y 24 años viven en España de 
espaldas a la política. Cuando a estos jóvenes se les preguntan los motivos por los que los jóvenes sienten que vale la pena movilizarse o arriesgarse, el porcentaje más alto lo obtiene por conseguir trabajo $(64,6 \%)$, seguido de conseguir el fin de las guerras (35\%) y seguido a su vez muy cerca por el poder tener acceso a una vivienda $(32,8 \%)^{13}$.

La política aparece por tanto como algo vinculado con el mundo de sus padres, de los mayores, pero desgajado del mundo de las nuevas tecnologías y de la información, es decir, del nuevo mundo en gestación. Las utopías parece que se han agotado, y la autoafirmación de la propia individualidad, frente a un mundo que resulta problemático, permite al menos mantener viva la creencia en la posibilidad de una autonomía del yo.

\section{Elección de la profesión y socialización profesional}

En realidad los estudiantes de psicología eligen doblemente su profesión. La primera vez al finalizar sus estudios de bachillerato, cuando se matriculan en la Facultad; la segunda cuando, tras finalizar su tercer año de estudio en la Facultad, se ven obligados a elegir la especialidad. La Fundación Universidad-Empresa realizó en 2005 una encuesta entre los estudiantes de bachillerato en la que se puso de manifiesto la desorientación profesional que reina entre ellos, pues tres meses antes de tener que decidir qué carrera universitaria elegirán, un $48 \%$ de los estudiantes de bachillerato afirma que no saben lo que van a estudiar. Un 50\% afirma que elegirá sus estudios por vocación, mientras que tan sólo un $26 \%$ afirma que tendrá en cuenta las posibles salidas profesionales. En este sentido el Informe Pigmalión de 2003 señala que un 37\% de los universitarios han estudiado carreras con escasas salidas profesionales sin saberlo, y que el $87 \%$ desconoce las oportunidades profesionales que le brinda su carrera ${ }^{14}$.

Algo más de la mitad de los estudiantes se decanta por el estudio de la Psicología clínica, seguidos a gran distancia por aquellos que eligen como especialidad la Psicología social $(11,7 \%)$ la Psicología del trabajo $(10,7 \%)$ la Psicología educativa $(3,2 \%)$ y la Psicología cognitiva $(2,4 \%)$. Califican la formación recibida en la Facultad con un aprobado (el 63\%), un notable (el 24\%), y el 11,4\% califica la formación que recibe con un suspenso. Los chicos valoran por lo general esta formación peor que las chicas. Para los estudiantes la enseñanza que reciben en la Facultad se caracteriza por ser sobre todo teórica, por estar más centrada en el pro-

13 Véase el estudio coordinado por MEJíAs, E., Juventud y política. El compromiso con lo colectivo, Madrid, INJUVE-FAD, 2005, Cf. también El País, 1-II-2006, p. 25.

14 Cf. El País, 8-VII-2005, p. 34. 
DEBATES E INFORMES

fesor que en el estudiante, por ser más directiva que participativa, más aburrida que creativa, más decepcionante que estimulante. Sin embargo, no todo es negativo en sus apreciaciones, ya que la consideran más científica que ideológica, más actualizada que desfasada, más democrática que autoritaria. Se explica así que la nota media que recibe la formación académica sea un aprobado alto.

¿Por qué eligieron estos estudios? La respuesta claramente dominante es de carácter altruista: porque me permite ayudar a los demás a solucionar sus problemas (40,4\%). La diferencia entre chicos y chicas en este punto es importante pues alcanza casi 12 puntos. Sobre todo en las chicas la motivación para realizar esta elección está correlacionada con la función que principalmente otorgan a su futura profesión: «servir a los ciudadanos» (59,5\%). Si pasamos, tras esta opinión bastante generalizada, a la que le sigue encontramos que la han elegido porque quieren contribuir a entender y mejorar la sociedad (19,4\%). Es esta una opinión que concuerda también con la segunda función que asignan a la profesión de psicólogo: contribuir a construir una sociedad más democrática e integrada (23\%). Con esta dimensión social y progresista coexiste otra dimensión que podríamos calificar como psicologista, individualista y centrada en el yo, que es la posición en que se sitúan en torno al $15 \%$ de los estudiantes, y que se expresa bajo la forma de un cierto malestar psicológico personal. Curiosamente esta dimensión predomina sobre todo entre los varones. Es sintomático que los chicos casi doblan a sus compañeras de clase cuando afirman que eligieron la profesión porque me permite conocerme mejor y realizarme. Conviene tener en cuenta que más de un $7 \%$ afirma que en su familia predominan los conflictos, y otro porcentaje del 5\% afirma que es un espacio físico sin convivencia en el que cada uno va a lo suyo. Conviene recordar que para un 6,6\% de los estudiantes, porcentaje en el que los chicos doblan a las chicas, en las familias españolas existe un fuerte choque generacional. Un 12,4\% afirman que se encierran con mucha frecuencia en su habitación. Para la solución de sus problemas confían en primer lugar en los amigos, seguidos de la familia. Pero, únicamente un porcentaje del 5\% están dispuestos a acudir al psicólogo. Atribuyen el éxito personal de los sujetos a su esfuerzo, su motivación y su capacidad de elección $(59,2 \%)$ y, a una considerable distancia, lo atribuyen al entorno familiar y educativo (20,9\%). Son menos aún los que lo hacen radicar en el peso de las relaciones sociales $(12,9 \%)$. Este recurso al individualismo y a la meritocracia se podría quizás explicar a partir de la fuerte valoración que ellos mismos hacen de su propio esfuerzo para acceder a la Universidad y para aprobar. La mayoría percibe sus estudios como una promoción personal en relación con su origen social lo que puede conllevar a un cierto desclasamiento respecto a la familia y su entorno cultural, desclasamiento que en ocasiones se intenta compensar mediante un reclasamiento en una cierta autoafirmación del yo psicológico. 
Los estudiantes de psicología consideran que su rendimiento escolar es bueno $(54,4 \%)$, apreciación que domina sobre todo entre las chicas. Y piensan que la principal causa del fracaso escolar radica en la ausencia de compromiso del estudiante con el estudio, es decir, una vez más predominan las explicaciones individuales sobre las sociales. Más del $50 \%$ señalan que la media de su expediente académico en la Facultad es de notable (52\% de las chicas frente al $45 \%$ de los chicos). Los encuestados dicen asistir regularmente a clase, aunque un $10 \%$ reconoce faltar bastante, pero ello se puede deber a que la mayor parte de las encuestas fueron sobre todo realizadas durante el tiempo dedicado a alguna clase, bien de teoría, bien de prácticas.

Ya hemos señalado que la mayor parte de los estudiantes eligen la especialidad de Psicología clínica. Por este motivo hemos introducido en la encuesta una serie de items para tratar de conocer su concepción de la salud, la enfermedad mental, las psicoterapias y la personalidad. En relación con la personalidad consideran que está moldeada por las condiciones sociales en las que vive el sujeto, y también que es el resultado de las interacciones con los demás. Únicamente un porcentaje reducido atribuye la formación de la personalidad a un trabajo sistemático sobre el yo $(9,2 \%)$. Las terapias que les inspiran mayor confianza son las de tipo psicológico, seguidas de la medicina tradicional. Los futuros psicólogos reprueban el autotratamiento y la automedicación, así como el denominado intrusismo, especialmente de curanderos y brujos. La medicina naturista, la homeopatía y las terapias orientales son elegidas no obstante por casi un $18 \%$. Piensan que el principal factor que provoca las enfermedades mentales son los traumas infantiles y las carencias afectivas, seguido de las condiciones sociales y afectivas deterioradas, y en tercera posición los factores hereditarios.

Los futuros psicólogos son predominantemente racionalistas, pero algunos porcentajes de determinadas respuestas resultan inquietantes pues ponen de manifiesto la presencia de un cierto irracionalismo que contradice abiertamente el carácter científico de la profesión: Un 36\% afirma creer en el contacto con los espíritus; un $33 \%$ cree en la telepatía; un $24 \%$ en la adivinación; un $23 \%$ en la existencia de los ángeles; un $22 \%$ en la reencarnación; un $23 \%$ en la quiromancia; un $18 \%$ en la brujería, lo que no deja de ser un indicador que nos retrotrae al origen rural de sus padres; un $16 \%$ en la comunicación con los extraterrestres; un 9,7\% en la existencia de los demonios, etc. Así pues uno de cada tres estudiantes trata de compatibilizar el pensamiento mágico-mítico con el pensamiento científico propio de su profesión universitaria. El interés por las ciencias y las pseudociencias ocultas, no solo refleja un cierto aprecio por lo irracional, responde también a la capacidad de englobar los fenómenos para-normales en el interior de los códigos psicológicos, lo que permite ampliar el radio de acción de la profesión. Por otra parte, a pesar de estas creencias, los estudiantes son en su mayoría moder- 
DEBATES E INFORMES

nos, pues, al igual que la mayor parte de los jóvenes universitarios, utilizan Internet y entran en la red varias veces a la semana, se sirven del correo electrónico, aunque solo una pequeña parte participa en foros de discusión. El contacto con las nuevas tecnologías es muy frecuente. Al mismo tiempo, como ya hemos señalado, parecen haber superado en su mayor parte la tragedia que supuso la guerra civil española, a pesar de que es significativo que un 5\% responda a esta pregunta con un significativo no sabe o no contesta.

A la hora de resolver alguna preocupación o problema personal tan sólo cerca de un 5\% de los estudiantes acudirían a un psicólogo, pero es significativo que el porcentaje crece a medida que se desciende en la escala de la estratificación social, lo que indica que son los estudiantes de un origen social más bajo los que más se identifican con la profesión. El porcentaje de chicos que acudirían al psicólogo es ligeramente superior al de las chicas, pero también son más chicos que chicas los que intentan resolver solos sus problemas, porcentaje que también aumenta a medida que se desciende en la escala social.

Los estudiantes son conscientes de la dificultad que entraña encontrar un puesto de trabajo que les permita desarrollar las capacidades adquiridas durante el tiempo de su socialización profesional en la Universidad. De hecho la encuesta se realiza prácticamente coincidiendo con una fuerte movilización de los estudiantes de psicología que piden para su profesión un estatuto de profesión sanitaria.

En el futuro, cuando terminen los estudios universitarios, les gustaría sobre todo encontrar trabajo en un organismo público $(50,5 \%)$, en una empresa propia con otros colegas $(24,8 \%)$ y en tercer lugar como profesional liberal $(11,2 \%)$. Esta última opción es, en el caso de los chicos su segunda opción, una opción preferida por tanto, a la de trabajar en una empresa con otros colegas.

El acceso a la profesión, a un trabajo profesional de psicólogo, resulta enormemente problemático pues existe en el mercado de trabajo una saturación de titulados. Los estudiantes son conscientes de este bloqueo, al igual que son conscientes de la precarización laboral y están cansados de los enfrentamientos verbales entre los políticos sin que se resuelvan los problemas reales, y entre ellos es el de su plena integración en la sociedad.

\section{Estudiantes a la búsqueda de un yo psicológico}

¿Quiénes son y cómo son el grupo de estudiantes que hemos definido como outsiders, es decir, el colectivo de estudiantes más psicologizado? Vamos a presentar a grandes rasgos su singular perfil.

Son estos estudiantes los que ven más práctica la enseñanza de la psicología, y a la vez los que la perciben más desfasada y decepcionante. Tienden a puntuar 
con un aprobado la enseñanza que reciben en la Facultad, es decir, le dan la peor calificación de los cuatro grupos, pero a la vez son también el grupo que peor valora su propio rendimiento académico, a pesar de que la nota media de los expedientes de este colectivo se sitúa entre el sobresaliente y el aprobado.

En términos generales estos estudiantes creen en la meritocracia, en el esfuerzo personal, en el compromiso con el estudio que consideran el mejor antídoto contra el fracaso escolar. A la hora de valorar el fracaso se responsabilizan, por tanto, en primer lugar a sí mismos, pero culpan en segundo lugar a los profesores que transmiten una enseñanza aburrida y poco actualizada. También son los que más consideran la baja autoestima como un factor de fracaso. Son, por tanto, los que más importancia confieren a las explicaciones individuales y psicológicas sobre el éxito y el fracaso escolar.

En realidad bajo un mismo modo uniforme de concebir la psicología como un medio privilegiado para maximizar las capacidades individuales subyacen en realidad dos subgrupos bien diferenciados por su distinto origen social: de un lado, están estudiantes procedentes de las capas sociales más bajas de las clases trabajadoras con escasa cualificación profesional; del otro, estudiantes pertenecientes a la burguesía tradicional con escaso capital económico y fuerte capital cultural. Los primeros proceden predominantemente de familias de origen rural que emigraron a Madrid a comienzos de los años sesenta, familias que han trabajado enormemente y que gozan en la actualidad de una posición económica relativamente desahogada. Los segundos provienen de la clase media tradicional con padres ya jubilados, y sobre todo con madres dedicadas a la enseñanza. En su casa familiar hay biblioteca pero pocos lavavajillas. En estas familias no entran prácticamente las cámaras de vídeo pero si los ordenadores conectados a la red. La distancia entre padres e hijos es enorme en este grupo y, posiblemente el abismo generacional se vea ahondado por las nuevas tecnologías y por nuevos valores. Son también ellos los que más acuden al no sabe/no contesta cuando se les piden precisiones sobre sus padres. Todo parece indicar que viven en su familia la crisis de la familia tradicional por lo que se producen en su interior rupturas familiares o fuertes desajustes entre los padres. Son los que opinan en mayor medida que la familia es una institución social en crisis y también los que son una minoría mayoritaria a la hora de opinar que la familia debería desaparecer. En términos generales el colectivo de estudiantes psicologizados esperan tener más éxito económico que sus padres cuando al fin logren independizarse.

$\mathrm{Su}$ individualismo se pone bien de manifiesto en que son los menos dispuestos a vivir con un grupo de amigos. Prefieren vivir con el compañero o la compañera y en último término con sus padres, pues, pese a las relaciones problemáticas, han conseguido una coexistencia con autonomía, posiblemente tras haber superado fuertes enfrentamientos. En sus familias están bien representadas las 
mascotas quizás porque ayudan a suplir las carencias afectivas. Se definen a sí mismos como libertarios individualistas en un porcentaje muy alejado del resto de los grupos, pues en ocasiones lo triplican.

Les gustaría que su vivienda estuviese decorada con mezcla de estilos aunque son el grupo que más elige un estilo ultramoderno y vanguardista, y los que más eligen el adjetivo fantasioso para definir su estilo de vida. Nos encontramos por tanto con estudiantes creativos, soñadores, que en muchas ocasiones se sienten solos e incomprendidos. Son ellos los que más asisten a conferencias y también los que en mayor porcentaje eligen vivir sin domicilio fijo. Son los que consumen menos tabaco, pero en contrapartida son los que consumen más alcohol y más drogas blandas. La acción conjunta del alcohol y las drogas blandas acrecienta su sensación de marginalidad y singularidad. Probablemente la rebeldía generacional se manifestó ya en el bachillerato pues en su mayoría han estudiado en Institutos públicos. Su independencia los lleva a trabajar para tener unos ingresos complementarios para sus gastos. Son ellos los que más asisten a conciertos de música juvenil y los que más chatean. El ordenador es su principal medio de comunicación. Leen poca prensa y ven poco la televisión pero con bastante frecuencia leen novelas policíacas y de aventuras, así como poesía y libros de ensayo. Detestan las novelas románticas que tanto gustan a los libertarios comunitaristas con quienes comparten algunos grandes rasgos y estilos de vida propios de su radicalismo antiautoritario. También son buenos lectores de comics. Ellos mismos escriben poemas y con mucha frecuencia escriben un diario en el que refuerzan su sentimiento de singularidad. Son el colectivo que menos deporte practica y el que menos baila, sin embargo les gusta el cine, especialmente el social, pero también las películas de terror. Las películas que más les gustan son las psicológicas que no estén exentas de un poco de morbosidad. Detestan las películas del oeste y los musicales. De los programas de televisión uno de los que les resulta más atractivo es Gran Hermano. En contrapartida no les gustan ni los deportes ni el fútbol. Con bastante frecuencia salen de copas, y pasean por la gran ciudad, quizás para mejor experimentar la libertad. Su música preferida son los ritmos latinos, pero también el hip/hop y el Rap, así como la música folk y el rock. No les gustan los museos. Su pintor predilecto es Dalí, seguido de Van Gogh, es decir, artistas locos o extravagantes que se sienten únicos. A la hora de elegir una fotografía son los que más rechazan a una madre amamantando un niño y los que más eligen la fotografía de la palma de la propia mano o a un alfarero modelando el barro. Decididamente están en las antípodas de la familia tradicional representada por sus padres que ellos perciben como un fracaso. Sin embargo estos estudiantes no se sienten bien: son también ellos los estudiantes más enfermizos, los que más acuden al médico, y también al psicólogo, pero a la vez los que menos van a la consulta del dentista. No soportan el dolor ni la frustración. Son los que 
menos van a misa pues el $87 \%$ no lo hacen nunca, aunque hay entre ellos un pequeño porcentaje que se siente religioso, pero con una religiosidad mística, oriental, un tanto panteísta.

No les gusta viajar por España, ni salir al extranjero. Se diría que sus rutinas están establecidas a través de moverse en círculos muy restringidos. Algunas veces ayudan a hacer la compra, pero nunca cocinan, ni riegan las plantas. Como en sus casas no hay lavavajillas son el grupo que más friega los platos, pero el que menos ayuda a limpiar la casa. Su libro preferido es el Diario de un skinhead, seguido del omnipresente Código Da Vinci. También son los que más eligen refugiarse como Robinson Crusoe en una isla desierta. Para ellos la cultura debe dejar un gran margen al libre desarrollo personal, pero a la hora de elegir un tipo de cocina se decantan por la opción más tradicional y eligen la seguridad de la cocina de la abuela, frente a gustos más exóticos y arriesgados. Son los que más se adscriben al vegetarianismo.

Desde el punto de vista político se declaran republicanos y libertarios muy por encima de la media. Son los que se sitúan en la izquierda más radical y a la vez los que menos se interesan por la política oficial. No se sienten por tanto representados en el actual espectro político parlamentario y se declaran a sí mismos, en un 30\%, como apolíticos. Junto con los anarquistas son el colectivo que más hace suyo el lema de los movimientos antiglobalización: Otro mundo es posible. Su ideología política preferida es el socialismo democrático seguida del individualismo libertario.

Las instituciones que más valoran estos estudiantes, que hemos definido como outsiders, pero que también se podrían definir como ensimismados pues parecen permanecer encerrados en su propio mundo interior, es el sistema sanitario, seguido del sistema educativo y de los tribunales de justicia. Un dato llamativo y aparentemente contradictorio es que son quienes más valoran el sistema penitenciario, y los que menos valoran a la Iglesia y a la policía. Son también los más favorables a la pena de muerte y los más contrarios a los nacionalismos. También son los más favorables a la persecución de la inmigración ilegal y los que están menos de acuerdo con la prohibición del botellón. ¿Cómo se explica que los más contrarios a la autoridad sean a la vez los más favorables a las instituciones de orden y de control social? Quizás se podría avanzar una respuesta si consideramos el hecho de que son estos estudiantes los que más robos han sufrido (55,3\%) así como amenazas $(36,2 \%)$. Son también los que presentan los porcentajes más altos de acoso en la escuela, los que han sufrido más ataques informáticos, y los que dicen haber sido objeto de una mayor violencia de género.

A partir de estos indicadores se puede concluir que conviven con el malestar en el interior de una especie de individualismo amenazado. Están solos y no se sienten protegidos ni seguros, Únicamente cuentan con la autoafirmación de su identidad. Se aferran por tanto a su autopercepción como diferentes, y pese a que 
no acatan la autoridad quieren que la autoridad los proteja con la mayor contundencia de los peligros que los rodean.

Los outsiders son los estudiantes más secularizados, los más contrarios a que se imponga la asignatura de religión en la ESO, los más contrarios a la financiación de la enseñanza concertada. Tanto el subgrupo proveniente de las clases trabajadores como el de las viejas clases medias estudiaron en centros públicos de enseñanza donde se ha producido una cierta degradación en los diez últimos años, pero en los que han logrado sobrevivir. Son también los más sensibles a las desigualdades sociales y a la amenaza del cambio climático. Si se celebrasen, en el momento en el que se pasó la encuesta, elecciones generales la mitad se abstendría, y la otra mitad votaría a Izquierda Unida. El político que más valoran es Ghandi, seguido de La Pasionaria. Son ellos también los más ardientes partidarios del matrimonio homosexual, el aborto y el divorcio, y los que muestran un mayor desacuerdo con el actual proyecto de Constitución Europea. Defienden el control de la telebasura por el Estado, el derecho al voto de los emigrantes, y en un porcentaje elevado están en desacuerdo con la financiación de la Iglesia por parte del Estado (74,5\%). También son ellos los que están más en desacuerdo con las ONG y con la flexibilización del trabajo. Son los máximos defensores del laicismo, de la igualdad entre los sexos, de la liberalización de las drogas, y los que se muestran más indiferentes a la ilegalización de HB. Su distancia con la Iglesia se pone también de manifiesto en que un porcentaje significativo está en desacuerdo con el matrimonio religioso $(32,4 \%)$. Todo parece indicar que en este colectivo se agrupan una buena parte de los estudiantes de ambos sexos que se definen a sí mismos como homosexuales.

El principal problema al que a su juicio se enfrentan actualmente los jóvenes, y en esto coinciden con los demás grupos, es el de la vivienda, seguido el de la precarización laboral, y el paro. Les gustaría vivir independientes, pero tanto las viviendas caras como el trabajo mal pagado se lo impiden. Pertenecen por tanto a familias de trabajadores o de la burguesía que comparten la creencia de que el trabajo es el medio fundamental para vertebrar una identidad. Son sensibles a los problemas de la pobreza y la exclusión social, y defienden el papel protector del Estado social, pero a la vez comparten con la contracultura el interés por la medicina naturista y la homeopatía. Son ellos los que más creen en la reencarnación, en la quiromancia y en la telepatía. Se declaran idealistas, pacifistas, ecologistas. Son los que menos creen en la predestinación y en la vida después de la muerte, y sin embargo son también los que están más dispuestos a aceptar la comunicación con los extraterrestres quizás porque su comunicación con los terrestres que los rodean les resulta problemática. No están dispuestos a renunciar a su yo, ni tampoco a dejar el futuro en manos de adivinos. En su existencia dan prioridad al desarrollo del autocontrol que me permite descubrir mi interior. 
Los jóvenes outsiders son conscientes de que el éxito personal proviene del esfuerzo, de la motivación, de la capacidad de elección, pero también de la suerte, y de saber aprovechar las oportunidades. Quizás porque están un poco perdidos en su soledad valoran sobre todo el capital relacional, seguido del capital psicológico y el cultural. En último lugar queda el capital económico. Se podría pensar, por tanto, que pertenecen a la generación de jóvenes postmaterialistas que se comunican sobre todo a través de mensajes y de chats. Defienden su mundo personal, su ateísmo, su agnosticismo militante. Valoran mucho a los amigos porque tienen pocos. Y pese a sus conflictos internos también valoran la vida en familia. Estos jóvenes que rondan los veinte años y disponen para sus gastos entre 40 y 50 euros semanales, han elegido en su mayoría como especialidad la Psicología clínica. Para ellos las enfermedades mentales son sobre todo el resultado de condiciones sociales y afectivas deterioradas y piensan que el psicólogo es ante todo un profesional que sirve para ayudar a los demás. Aspiran a trabajar en un organismo público o en una empresa propia con otros colegas. No son muy partidarios de las salidas al extranjero quizás porque no dominan ningún otro idioma, fuera del castellano, y porque han optado por vivir un encapsulamiento localista combinado con la navegación por la red. Sería preciso que sus familias y los profesores de la Facultad los estimulasen pues una parte de estos estudiantes, los que tienen peor expediente académico, procedentes en su mayor parte de las clases populares, abandonan los estudios en los últimos cursos. En el curso 2006-2007, de los 3.242 estudiantes matriculados en la Facultad de psicología de la Universidad Complutense, 1.010 estaban matriculados en $5 .^{\circ}$ curso, de modo que la media de estudiantes en este curso casi dobla a la del resto de los cursos pues se acumulan en el último año de la carrera los estudiantes con asignaturas pendientes. Estadística, Psicometría y Neurociencia en el primer ciclo, y Lenguaje y Modificación de conducta en el segundo son algunas de las asignaturas que cuentan con más repetidores. «Estudiando en la Facultad de Psicología, -escribía el anteriormente citado estudiante de la Complutense que realiza la especialidad de Psicología Clínica-, en los últimos cursos se respira la frustración. La mayoría no va a clase, no se esfuerzan en los estudios tanto como al principio, y ya no se dan las ilusiones del primer curso. El paro se cierne sobre todos. (...) Cada vez obligan a formarse más y cada vez hay menos esperanzas de tener un empleo. Mi percepción es que muchos se ven ya trabajando en una tienda de ropa, o de camareros, o de cualquier otra profesión no relacionada con la Psicología. España es el primer exportador de Psicólogos de Europa, y no hay trabajo para todos». Y por esto muchos se rinden. Se rinden sin renunciar a su identidad profesional por la que optaron vocacionalmente. La Psicología se convierte entonces para ellos más en un refugio a su malestar de vivir que en una profesión a ejercer o en un saber experimental. Buscan en la Psicología respuestas a problemas que los desbordan, 
DEBATES E INFORMES

problemas que la socialización profesional no puede resolver. No se dan cuenta de que bajo el espejismo del mundo interior la propia socialización profesional favorece que permanezca intacta la irracionalidad social que engloba también a la irracionalidad existente en nuestras instituciones académicas, unas instituciones marcadas a través de los años por inercias heredadas, y que, demasiadas veces, se perpetúan ajenas a los intereses de los estudiantes que las frecuentan.

Contradicciones en la cultura: estilos de vida y estilos de pensar

A la hora de elaborar este cuestionario dirigido a los estudiantes universitarios intentamos combinar a la vez las propuestas de Pierre Bourdieu sobre los estilos de vida, y las de Mary Douglas sobre los estilos de pensar ${ }^{15}$. Consideramos que ambas perspectivas se complementan y enriquecen entre sí, pues los estilos de vida conforman estilos de pensar, y, a la vez, los estilos de pensar implican la referencia a un sistema de valores que se materializa en la acción social por medio de gustos y consumos, es decir, por medio de juicios de valor y de prácticas. En realidad los estrechos vínculos existentes entre el sistema de organización social y el sistema de categorías de pensamiento imperantes en una sociedad fue establecido por Émile Durkheim en Las formas elementales de la vida cotidiana, pero no sabemos demasiado sobre la correspondencia existente entre la estructura socioprofesional de nuestras sociedades y los diferentes sistemas de valores en concurrencia.

Una de las dimensiones que no suele ser introducida en los cuestionarios es el imaginario social de los encuestados, es decir, las aspiraciones, los sueños, los deseos profundos de los sujetos que están en buena medida conformados por sus condiciones de vida y trabajo, por su posición social, pero también por su socialización profesional y lo que esperan de su profesión. Pues bien, los sueños de los estudiantes de psicología hablan no sólo de su capital simbólico y cultural, sino también de su realidad material y social quizás con más fuerza que las apreciaciones puntuales sobre las prácticas y los consumos en la prosaica vida cotidiana.

Pierre Bourdieu fue quizás uno de los primeros sociólogos que se refirió a las estrategias de reproducción, es decir, a las prácticas por medio de las cuales los individuos tienden a conservar o incrementar, de manera consciente o inconsciente, el patrimonio de sus familias. Estas estrategias dependen del volumen de los tres capitales que conforman una posición social, es decir, del capital económico, del capital cultural y del capital social o relacional. Como señaló Bourdieu «la

15 Cf. Bourdieu P., La distinción. Criterio y bases sociales del gusto, Madrid, Taurus, 1988; y Douglas, M., Estilos de pensar. Ensayos críticos sobre el buen gusto, Barcelona, Gedisa, 1998. 
entrada en la carrera y en la competencia por la titulación académica de fracciones que hasta entonces han utilizado poco la escuela, ha tenido como efecto obligar a las fracciones de clase cuya reproducción estaba asegurada principal o exclusivamente por la escuela, a intensificar sus inversiones para mantener la particularidad relativa de sus titulaciones y, correlativamente, su posición en la estructura de las clases, llegando a ser así la titulación académica y el sistema escolar que la otorga una de las apuestas privilegiadas de una competencia entre las clases que engendra un aumento general y continuo de la demanda de educación y una inflación de las titulaciones académica» ${ }^{16}$.

La inflación de títulos de licenciados en Psicología es en España una realidad que golpea predominantemente a los sujetos que cuentan con menos capitales en las estrategias de reconversión. Y, aunque no contamos con indicadores fiables sobre los abandonos de la profesión, sobre los índices del fracaso escolar, todo parece indicar que el fracaso es alto si tenemos en cuenta el importante número de estudiantes que se agrupan en el último curso de la carrera sin llegar nunca a obtener el título de Licenciatura, el diploma que abre el camino para el legítimo ejercicio profesional. El fracaso aumenta a medida que se desciende en la escala de la estratificación social. Para evitar esas cifras alarmantes de abandono en muchos países europeos se impuso una licenciatura de ciclo corto (tres años) que abre paso a cursos de Máster y de Doctorado con resultados positivos ${ }^{17}$.

Sería preciso por tanto operar una profunda reforma en las Facultades de Psicología de nuestras Universidades y favorecer en ellas una mayor participación estudiantil, una mayor presencia de las prácticas, en suma, una mayor apertura a la comunidad, así como sustituir el viejo curriculum por un curriculum más abierto, pues en la actualidad los estudiantes no tienen suficientes asignaturas optativas ni capacidad para establecer su propio cursus académico, su propio itinerario intelectual, en función de los intereses de su propia formación. Los estudiantes demandan una enseñanza menos memorística y libresca, menos escolástica, en la que las prácticas y la incorporación de saberes de otras facultades rompan con la monotonía y el aislamiento, una enseñanza más abierta a otros códigos teóricos y prácticos, que pongan freno a la ortodoxia conductista convertida en una especie de corsé intelectual para la perpetuación del pensamiento único. Una reforma del curriculum profesional de los futuros psicólogos sensible a estas propuestas supondría sin duda para los estudiantes un mayor estímulo.

16 Cf. Bourdieu, P., La distinción. Criterio y bases sociales del gusto, pp. 122 y 130.

17 En este sentido parecen acertadas las propuestas de la Comunidad Europea adoptadas en Bolonia de acortar los años para la obtención del grado y escalonar con títulos intermedios las carreras universitarias. Sin embargo los estudiantes de psicología de la Complutense con mejores calificaciones se oponen a la ampliación de títulos pues consideran que dificultaría aún más el acceso a la profesión y devaluaría los actuales títulos. 
Mary Douglas se refirió en Estilos de pensar a cuatro tipos de sociedad que conforman un mapa cultural: En primer lugar se encontraría una sociedad jerarquizada, compartimentada y competitiva; en segundo lugar una sociedad igualitaria y participativa; en tercer lugar una sociedad de individuos competitivos; y en cuarto lugar una sociedad de individuos aislados que prefieren evitar los controles opresivos ${ }^{18}$. En realidad estos cuatro tipos ideales definidos por los dos ejes de la participación-competición y del individualismo-comunitarismo coinciden en buena medida con la tipología que hemos propuesto de los estudiantes de Psicología. Mary Douglas estableció así cuatro estilos de vida que denomina el individualista, el jerárquico, el igualitarista y el aislado. Si retomamos su clasificación, el estilo de vida que domina entre los estudiantes de la Facultad de Psicología es el igualitarista que ella misma define así: «es el estilo igualitario, de enclave, que está en contra de la formalidad, la pompa y el artificio, que rechaza las instituciones autoritarias y prefiere la simplicidad, la franqueza, las amistades íntimas y los valores espirituales». La tesis de Mary Douglas es que a cada mundo social, a cada organización social, le corresponde un tipo cultural, de modo que las distintas culturas compiten entre sí en el espacio social por dotarse, frente a las otras, de mayor legitimidad. Por otra parte una persona no puede pertenecer simultáneamente a dos culturas por mucho tiempo ${ }^{19}$.

En la actualidad coexisten dos concepciones del mundo que se oponen entre sí. Una ofrece una sociedad con alto crecimiento, avanzada tecnología y libre empresa, con una postura que, en relación con los objetivos y el gobierno, está orientada a los negocios. Podríamos definir esta concepción como una concepción insolidaria. Otra ofrece un futuro con menos crecimiento material y tecnológico y en el cual los gobiernos se preocupen más por el bienestar social y ambiental, por una redistribución de la riqueza que beneficie a las naciones más pobres, por la toma de decisiones participativa, y por los valores no materialistas ${ }^{20}$. Podríamos definir esta concepción del mundo como la concepción solidaria. Los futuros psicólogos son socializados en la concepción solidaria del mundo, pero el drama de su profesión es que para que sea socialmente aceptada y prestigiosa, para que se desarrolle, para que sea reconocida como útil por los poderes fácticos, tiene que aceptar, o guardar silencio, sobre la concepción insolidaria del mundo capitalista que hoy por hoy ejerce implacable su hegemonía, incluso para el acceso a la profesión de psicólogo.

18 Cf. Douglas, Estilos de pensar. Ensayos críticos sobre el buen gusto, p. 58.

19 Cf. Douglas, Estilos de pensar. pp. 96 y 59. «La adhesión cultural penetra toda conducta, escribe Mary Douglas, incluso el acto de ir de compras», p. 98.

20 Retomamos estas dos concepciones del mundo en Buss, D. M., y otros, citada por la propia Mary Douglas, Cf. Douglas, Estilos de pensar. p. 114. 
Mary Douglas denomina a los estudiantes que hemos definido como psicologizados los aislados, situándolos culturalmente próximos a los disidentes. Por su parte Merton los denomina retraídos, y los sitúa en proximidad a los rebeldes. Ni Mary Douglas ni Merton parecen haber percibido esta dimensión que privilegia el mundo interior a la hora de definir a esos colectivos respectivos que están aislados del mundo social en buena medida porque no se pueden incorporar a él con facilidad. Sin embargo sus análisis constituyen un importante punto de apoyo para fundamentar la tipología que hemos adoptado. Aún más, podríamos intentar explicar el proceso de psicologización como una especie de inversión del proceso de desviación analizado por Merton. Recuérdese que para Merton la conducta desviada surge cuando, dadas unas metas culturales, por ejemplo el éxito económico, los individuos no poseen los medios institucionales que les permitan alcanzar esas metas, por lo que recurren para lograrlas a vías irregulares, es decir, a procesos de desviación social. Pues bien, se podría decir que en el caso de los psicologizados se produce un proceso semejante pero inverso al de quienes protagonizan las conductas desviadas de modo que al diferir sus metas culturales de las metas propias de la cultura dominante, y al no aceptar tampoco los medios convencionales para alcanzar esas metas, los futuros psicólogos quedan al margen, viven ensimismados y reducidos a su yo psicológico, un yo que interiorizan y psicologizan dotándolo así de una profundidad sin término, es decir, conforman un abismal mundo interior que niega el mundo exterior y en buena medida lo sustituye. Al carecer de soportes relacionales, al carecer de apoyos materiales, los estudiantes se encierran en su propio universo simbólico y cultural, afirmado por las nuevas tecnologías mediante las cuales se mueven en el espacio virtual. Los propios códigos psicológicos se convertirían en el interior de este proceso en un importante refuerzo de todo un estilo de vida y un estilo de pensar.

Se dirá que el porcentaje de estos estudiantes es claramente minoritario si lo comparamos con el perfil dominante. Y sin embargo puede muy bien marcar una tendencia. De hecho si consideramos el dinero, el capital económico, como el principal signo de estatus en las sociedades capitalistas, no cabe duda que se está produciendo un proceso de degradación económica de las profesiones. El diferencial de salario de quienes tienen estudios universitarios respecto a los trabajadores con estudios inferiores a educación Secundaria Obligatoria (ESO) ha caído un 40\% en España entre 1997 y 2004, según el informe de La Caixa. Sin embargo aún siguen existiendo fuertes diferencias ente los salarios de los universitarios y los que no tienen estudios, o solo han estudiado hasta la ESO, pues en 2004 los ingresos de los universitarios eran superiores en un $60 \%$ al de los que sólo habían cursado la ESO. Sin embargo la tendencia a la depreciación de la fuerza de trabajo cualificada y avalada por títulos universitarios sigue avanzando. Según un informe de Comisiones Obreras en torno a 1.370.000 asalariados con estudios universita- 
rios desempeñan una ocupación inferior a su cualificación profesional. Hace 10 años el $19 \%$ de los españoles entre 25 y 64 años tenían estudios universitarios. En 2004 el porcentaje había subido al 26\%, por encima del $25 \%$ de media en los países de la $\mathrm{OCDE}^{21}$.

Robert K. Merton estaba interesado en mostrar que algunas estructuras sociales inducen a adoptar conductas conformistas o inconformistas en función de si hay disociación o no entre las aspiraciones culturalmente prescritas y las vías socialmente estructuradas de realización de estas aspiraciones ${ }^{22}$. En el caso de la formación de los futuros psicólogos, el análisis de la socialización profesional que se basa en las tendencias que se van consolidando desde los primeros a los últimos cursos, prueba un hecho importante: los estudiantes se van haciendo cada vez más pragmáticos, es decir, más conservadores, y a la vez más individualistas, más retraídos, y psicologizados. A medida que se acercan al ejercicio de la profesión tratan de adaptarse a la imagen socialmente dominante del profesional de ayuda que interviene en el marco de una relación personalizada de servicios. Los retraídos están en la sociedad, pero no forman parte de ella ${ }^{23}$. Por su parte Mary Douglas observa que los aislados se incrementan a medida que crece la precariedad en el empleo: «si el trabajo eventual se incrementara y el número de empleados temporales superara al de los empleados permanentes de la población, una proporción mayor de la comunidad se ubicaría en ese nicho cultural» ${ }^{24}$. Mary Douglas sitúa entre los aislados a pordioseros y vagos, pero también a personas de posición elevada como los miembros de la familia real. Sin embargo, como ya hemos señalado, ni Mary Douglas ni Merton percibieron la posible apertura en este ámbito cultural de la psicologización como estilo de vida y estilo de pensar, como afirmación activa de un modo de separarse y autonomizarse del mundo. Y sin embargo ¿no es esta separación del mundo, es decir, la puesta entre paréntesis de las estructuras sociales y de la dinámica social, la condición misma que asegura el éxito a los profesionales de la Psicología, es decir, eximir al sistema social y a las instituciones que los sustentan de toda responsabilidad en los malestares y sufrimientos psíquicos de los sujetos? Los outsiders, pese a ser minoría, señalan el avance de una cultura psicológica que se extiende socialmente para abarcar desde las grandes catástrofes a los pequeños malestares del yo. Pero también encarnan la gran con-

21 Cf. El País, 22-V-2007, p. 45.

22 Cf. Merton, en VV.AA., La familia, p. 72.

23 Cf. Merton, en VV.AA., La familia, pp. 96-97. Merton incluye en esta categoría a los psicóticos, los egotistas, los parias, los proscritos, los vagabundos, los borrachos crónicos y los drogados.

24 Cf. Douglas, Estilos de pensar, pp. 187-188. Según cifras de la OCDE, 6 de cada 10 jóvenes españoles trabajan con contratos temporales, es decir, el doble de la media de la OCDE. Sin embargo la tasa de temporalidad descendió del $66 \%$ en 2006 al $60 \%$ en 2007. Cf. las estadísticas y el cuadro de trabajadores con empleo temporal por edades y países en El País, 3-VI-2007, p. 73. 
tradicción que atenaza a los profesionales de la psicología clínica: ayudar a las personas que sufren eximiendo a la organización social de toda responsabilidad en la génesis de ese sufrimiento. ¿Cómo superar esta contradicción? En el caso de los estudiantes de psicología cabe la posibilidad de una alianza de los outsiders con los disidentes y con los socialdemócratas que podría hacer operativo el cambio cultural, empezando por el cambio en el espacio de socialización de los futuros psicólogos, es decir, en las Facultades de psicología. En este sentido el papel del cuerpo de profesores sería fundamental. Un avance en esta dirección favorable a una cultura de la solidaridad no solo contribuiría a crear un clima más acorde entre la socialización profesional de los futuros psicólogos y el altruismo de los estudiantes, sino que crearía también mejores condiciones para que la ciencia y los saberes psicológicos abandonasen la torre de marfil en la que parecen haberse instalado. El resultado sería también una mayor y más reflexiva vinculación de los futuros psicólogos con las demandas reales de la sociedad.

* Fernando Álvarez-Uría, Profesor Titular de Sociología en la Facultad de Psicología de la Universidad Complutense. Departamento de Sociología IV; Julia Varela, Catedrática de sociología en la Facultad de CC. de la Información de la Universidad Complutense. Departamento de Sociología VI; Ángel Gordo, Profesor Titular de Sociología en la Facultad de CC. Políticas y Sociología de la Universidad Complutense. Departamento de Sociología IV; Pilar Parra, Profesora Asociada de Sociología en la Facultad de CC. Políticas y Sociología de la Universidad Complutense. Departamento de Sociología IV.

Correspondencia: Fernando Álvarez-Uría Rico, C/ Chile 32, Ap. 42 D, 28016 Madrid.

Tf. 91 3598986. Móvil 679658561

** Fecha de recepción: 25-VI-2007 (aceptado el 22-XI-2007). 